\title{
Guest Editor's Introduction to Volume 5, Issue 2
}

\section{Special Issue on Male Violence against Women in Rural Places: New Directions in Research, Theory, and Policy}

\author{
Walter S. DeKeseredy \\ Anna Deane Carlson Endowed Chair of Social Sciences, \\ Director of the Research Center on Violence, and \\ Professor of Sociology \\ West Virginia University \\ UNITED STATES OF AMERICA
}

Contact author - Walter S. DeKeseredy; walter.dekeseredy@mail.wvu.edu

Those of us heavily immersed in the study of crime, law, and social control in rural and remote communities do not have to be reminded that rural criminological scholarship is now more voluminous and vibrant than ever before. This achievement can be attributed to a number of key factors, but undoubtedly, those who study violence against women in rural places have played a major role in making rural crime and justice studies what it is today. Every recent rural criminological anthology has at least one chapter on violence against women in the heartland and there are five scholarly monographs on this topic. What is more, academic articles on variants of male-to-female violence routinely appear in prestigious scholarly periodicals like this one and other widely read and cited interdisciplinary journals such as Rural Sociology, Rural Studies, Violence Against Women, and Critical Criminology. However, there has never been a special issue of any journal devoted entirely to disseminating contemporary international work in the field. Thus, this issue is a historical milestone and I am deeply honored to be a part of it.

Volume 5, Issue 2 of The International Journal of Rural Criminology features the work of a cadre of passionate researchers and theorists. It is beyond the scope of this introduction to summarize each contribution, but it must be emphasized that each one does not travel down the well-worn path of criticizing criminology's urban bias. Rural violence against women studies, like rural criminology in general, is now at the stage where it does not have to prove its value and waste valuable time and energy carping about being marginalized. As Callie Rennison and I state in our offering, rural criminology is also now at the point where it should be less celebratory and more self-critical.

Some brief historical background is necessary to set the stage for your journey through the materials that follow this introduction. It was not until the publication of Patricia Gagne's feminist ethnographic work in Appalachia that the international sociological and criminological communities started to develop rich social scientific knowledge about violence against women in rural communities (see her 1992 article in Volume 20 of the Journal of Contemporary Ethnography). Shortly after came Neil Websdale's (1998) path-breaking book Rural Woman Battering and the Justice System: An Ethnography. As we progress through this decade, there is now a much larger scholarly literature on male violence against women in rural places, and there 
is conclusive statistical evidence showing that rural women in both the Global North and Global South are more likely to be harmed by abusive male behaviors than are their urban and suburban counterparts. The seven contributions featured here are insightful and point us to new directions in future empirical and theoretical work in the field. I hope you find them to be as useful as I do.

All the contributors are grateful for the anonymous reviewers' comments and criticisms. Special thanks also go to Danielle M. Stoneberg for her outstanding editorial assistance. She and the reviewers made our pieces much better than they otherwise would have been. It is frequently stated that every scholarly project is a collective effort, and this one is no exception. 